\title{
1 Plasticity of maternal environment dependent expression-QTLs of tomato seeds
}

2

3 Mark G. Sterken ${ }^{1, \#}$, Harm Nijveen ${ }^{2,3}$, Martijn van Zanten ${ }^{4}$, Jose M. Jiménez-Gómez ${ }^{5,6}$, Nafiseh

4 Geshnizjani ${ }^{2}$, Leo A. J. Willems ${ }^{2}$, Juriaan Rienstra ${ }^{2}$, Henk W. M. Hilhorst ${ }^{2}$, Wilco Ligterink ${ }^{2, *}$,

5 Basten L. Snoek ${ }^{1,7, \#, *}$

6

$7 \quad{ }^{1}$ Laboratory of Nematology, Wageningen University, 6708 PB Wageningen, The Netherlands

$8{ }^{2}$ Wageningen Seed Lab, Laboratory of Plant Physiology, Wageningen University, 6708 PB Wageningen, The Netherlands

$9 \quad{ }^{3}$ Laboratory of Bioinformatics, Wageningen University, 6708 PB Wageningen, The Netherlands

$10{ }^{4}$ Molecular Plant Physiology, Institute of Environmental Biology, Utrecht University, 3584 CH Utrecht, The Netherlands

$11{ }^{5}$ Department of Plant Breeding and Genetics, Max Planck Institute for Plant Breeding Research, Cologne, Germany

$12{ }^{6}$ Institut Jean-Pierre Bourgin, INRAE, AgroParisTech, Université Paris-Saclay, 78000, Versailles, France

$13{ }^{7}$ Theoretical Biology and Bioinformatics, Institute of Biodynamics and biocomplexity, Utrecht University, $3584 \mathrm{CH}$ Utrecht, The Netherlands

$15{ }^{*}$ Corresponding authors

16

17 e-mail and ORCID:

18 mark.sterken@wur.nl; 0000-0001-7119-6213

19 harm.nijveen@wur.nl; 0000-0002-9167-4945

20 m.vanzanten@uu.nl; 0000-0002-2810-7374

21 Jose.Jimenez-Gomez@inrae.fr; 0000-0002-5033-7192

22 nafiseh.geshnizjani@gmail.com;

23 leo.willems@wur.nl; 0000-0002-9502-7745

24 juriaan.rienstra@wur.nl; 0000-0003-4870-8078

25 henk.hilhorst@wur.nl; 0000-0002-6743-583X

26 wilcoligterink@gmail.com; 0000-0002-0228-169X

27 1.b.snoek@uu.nl; 0000-0001-5321-2996

28

29

30

31

Key words: Tomato, eQTLs, High phosphate, Low nitrogen, Maternal environment, Seeds 


\section{Abstract}

33 Seeds are essential for plant reproduction, survival, and dispersal. Germination ability and

34 successful establishment of young seedlings strongly depends on seed quality and on

35 environmental factors such as nutrient availability. In tomato (Solanum lycopersicum) and many

36 other species, seed quality and seedling establishment characteristics are determined by genetic

37 variation, as well as the maternal environment in which the seeds develop and mature. The

38 genetic contribution to variation in seed and seedling quality traits and environmental

39 responsiveness can be estimated at transcriptome level in the dry seed by mapping genomic loci

40 that affect gene expression (expression QTLs) in contrasting maternal environments.

41 In this study, we applied RNA-sequencing to measure gene expression of seeds of a

42 tomato RIL population derived from a cross between $S$. lycopersicum (cv. Moneymaker) and $S$.

43 pimpinellifolium (G1.1554). The seeds matured on plants cultivated under different nutritional

44 environments; i.e. on high phosphorus or low nitrogen. The obtained SNPs were subsequently

45 used to construct a high-density genetic map. We show how the genetic landscape of plasticity in

46 gene regulation in dry seeds is affected by the maternal nutrient environment. The combined

47 information on natural genetic variation mediating (variation in) responsiveness to the

48 environment may contribute to knowledge-based breeding programs aiming to develop crop

49 cultivars that are resilient to stressful environments. 


\section{Introduction}

51 Seeds are essential for reproduction and dispersal of plants and function as survival structures to

52 overcome harsh environmental conditions unfavourable for plant growth. Well-timed

53 development and ripening of seeds, to ensure optimal seed performance and the ability to

54 germinate in a permissive environment, are therefore essential for plant fitness. Successful

55 germination strongly depends on seed performance, which is affected by environmental

56 conditions, such as temperature, water availability, light conditions, and the nutrient status that

57 the maternal plant experienced [1-5]. More specifically, seed performance/germination in species

58 such as tomato and the model plant Arabidopsis thaliana is determined during seed development

59 and maturation, and depends on temperature [6-8], photoperiod [9, 10], nutrient composition and

60 levels $[8,11,12]$. Seed quality, germination and seedling establishment traits also have strong

61 genetic determinants and (natural) genetic variation in quality traits, including Quantitative Trait

62 Loci (QTLs), have been reported [8, 12-17].

63 Phosphate and nitrate are essential plant nutrients with profound effects on plant growth

$64[18,19]$ and seed performance/germination traits $[8,12,15,20]$. In Arabidopsis it has been

65 shown that seeds produced by plants fertilized with higher-than-normal levels of phosphate

66 showed increased germination rates under stressful conditions [8]. Nitrate is known to have a

67 strong effect on seed germination and seed dormancy in multiple plant species [21], with high

68 concentrations of nitrate supplied to the mother plant leading to lower dormancy of the seeds

69 [11]. This is attributed to nitrogen effects on the gibberellin/abscisic acid (GA/ABA) balance in

70 the seeds; with higher endogenous nitrate levels resulting in lower ABA levels in seeds and

71 hence, shallower dormancy [22]. In Arabidopsis, altered nitrate levels experienced by the mother

72 plant also has a substantial effect on the levels of multiple metabolites and transcripts in the

73 seeds, with a notable reduction in nitrogen metabolism-related metabolites and genes [23]. 

and is a model organism for research on fruit-bearing crops [24-27]. However, in the process of

lost over time in modern varieties. This includes several seed quality traits [28-32]. Trait $15,17,53,54]$

94 studies. Moreover, measuring gene expression in RILs has enabled expression-QTL (eQTL) 
environments may aid our understanding of how genetic variation shapes the effects the

99 environment has on the appearance of phenotypes [57, 63, 64]. In plant (Arabidopsis) and worm

100 (Caenorhabditis elegans) model systems it has been shown that especially trans- eQTLs are

101 dynamic and can be highly specific for a certain environment [57, 63-68].

102

Although seed quality and seedling establishment characteristics are determined by both genetic variation and the maternal environment in which the seeds develop and mature [8, 12,

104 15], it is currently unknown if the maternal environment causes a perturbated eQTL landscape in

the progeny seeds and how the nutrient environment of the mother plant affects these landscapes.

106 We therefore followed an RNA-seq approach and quantified natural variation in mRNA levels in

107 the dry seeds of a tomato RIL population from a cross derived from S. lycopersicum (cv.

108 Moneymaker) and S. pimpinellifolium (G1.1554) parents [17, 49], that were cultivated either in a

109 low nitrogen or a high phosphorus environment. In this work we first present a high-density

110 RNA-seq-derived genetic map of tomato and subsequently we demonstrate how the genetic

111 landscape of gene regulation of tomato dry seeds is affected by the nutritional environment of the

112 mother plant.

113 Altogether, our detailed analysis of the genetic underpinning of plasticity in gene expression as

114 responsiveness to the maternal environment, attributed to the progeny seeds, may contribute to

115 knowledge-based breeding programs aiming to develop crop cultivars that are resilient to

116 stressful environments, including production of high-quality seeds under sub-optimal

117 environmental conditions. 


\section{Results}

121 An RNA-seq-derived genetic map of tomato

122 We performed an RNA-sequencing experiment to uncover the interplay between genetic

123 variation, the nutritional status of the maternal environment and mRNA abundances in progeny

124 tomato seeds. The used seeds were derived from tomato RIL plants of a cross between $S$.

125 lycopersicum (cv. Moneymaker; MM) and S. pimpinellifolium (G1.1554; PI) [17, 49] and their

126 parental lines. All maternal plants were pre-cultivated on standard nutrient conditions and upon

127 flowering transferred to either low nitrogen (LN) or high phosphate (HP) nutrition ( 100 RILs in

128 total, 50 RILs in each environment) [15].

129 In addition to estimating expression differences among individuals, RNA-seq reads allowed for

130 the identification of single nucleotide polymorphisms (SNPs) in transcribed genes of the parental

131 lines and the RILs. These SNPs were subsequently used to construct high density genetic and

132 physical maps of the RIL population, to facilitate QTL and eQTL mappings [13, 69]. In total, we

133 detected 43,188 consistent SNPs between the parental lines. These SNPs were subsequently used

134 to reconstruct the genotypes (i.e. determine the crossover locations) of the RILs in high detail

135 (Figure 1A). Across our RIL set, a balanced distribution of the parental alleles was observed

136 genome-wide, with the notable exception of chromosome 2, which had a substantial higher

137 frequency of PI alleles (Figure 1B). Overall, 2,847 recombination (crossover) events were 138 detected across the RIL population. As expected, the crossovers were found almost exclusively in

139 euchromatic regions of the chromosomes, causing severe distortion between the physical and

140 genetic maps, as described before [70](Figure 1C). On average, two recombination events were

141 detected per RIL per chromosome. Altogether, the population size and recombination events

142 provided 4,515 unique genetic markers and 4,568 distinguishable genomic loci/bins suitable for 143 mapping, improving the previously available map [71] (Supplementary table 1). The detected 

enables precise mapping of QTLs and eQTLs, especially towards the tips of the chromosomes.

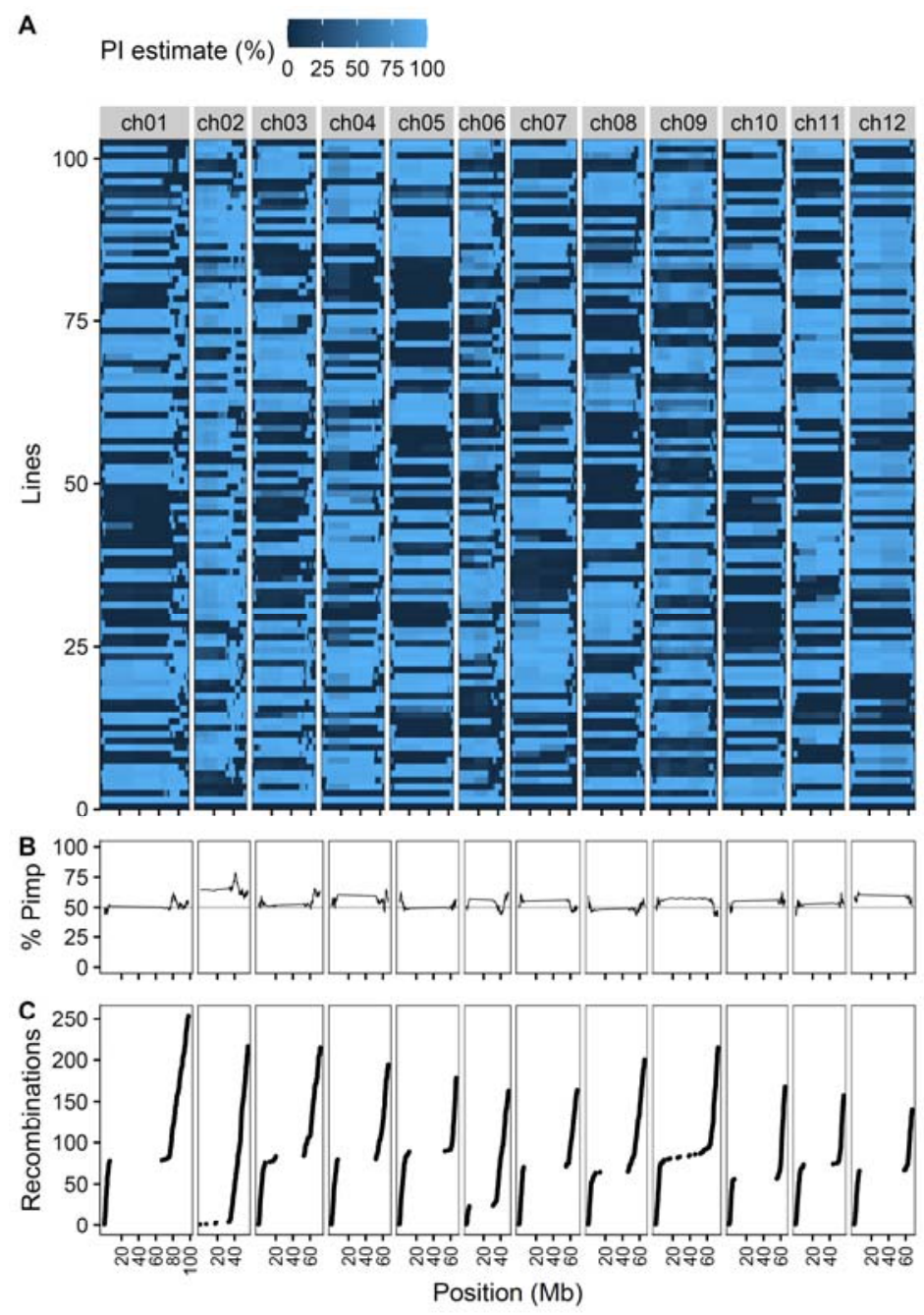

149 Figure 1: (A) Genetic map showing the genotype of the RILs and parental lines per chromosome (ch01 to ch12). Dark blue indicates MM (bottom horizontal line, with line number 0), light blue indicates PI (horizontal line above MM, with line number 100). Shades between dark and light blue visualize the certainty of the estimate that a locus corresponds to either MM or PI, depending on the SNPs identified (see legend above the panel; PI estimate). (B) Allele frequency (percentage) of $S$. pimpinellifolium (PI) alleles for each marker across the chromosomes, considering all RILs in the population. (C) Cumulative number of recombination events per chromosome for the whole population. Chromosome numbers are indicated above panels A, position on the chromosomes (in $\mathrm{Mb}$ ) is shown on the $\mathrm{x}$-axis below panel $\mathbf{C}$. 
The maternal nutrient environment affects $m R N A$ abundances in seeds.

160 Next, we compared mRNA abundances in all HP-treated lines (RILs and parental lines) with the mRNA abundances in LN-treated lines, to identify genes contributing to differences between the two environments. Principal Component Analysis (PCA) demonstrated the presence of a substantial effect of the maternal nutrient environment on transcript levels in seeds (Figure 2A). A linear model was used to identify which mRNAs were differentially expressed between the two maternal environments. A multiple-testing correction was applied and differential expression of

to depend on the nutritional conditions the mother plant experienced during the seed maturation phase (i.e. LN or HP) (Supplementary table 3). Of these 2,871 mRNAs, 922 were more abundant in seeds developed and ripened in HP conditions compared to LN, and 1,949 mRNAs were significantly more abundant in LN conditions compared to HP. The mRNAs of genes that were more abundant after LN treatment were among others enriched for Gene Ontology (GO) terms: 'chloroplast', 'ATP binding', 'proteasome' and 'nitrate transport' (Supplementary table terms: 'cellular response to hypoxia', 'pectin esterase activity' and 'glucosinolate metabolic process' (Supplementary table 4).

We also inquired the differences of the mRNA abundances between the MM and PI parental lines, within and between treatments. To this end, we again employed a linear model, but

178 were less stringent in the statistical thresholds (as there were no confounding effects). We found $1792,976 \mathrm{mRNAs}$ differentially expressed between the two parental lines regardless of treatment and 382 mRNAs that were differentially expressed between the lines due to treatment (linear model, 
'transcription factor activity', 'oxidation-reduction', 'protein -binding', '-phosphorylation', ‘ubiquitination', 'chloroplast', 'circadian rhythm', and 'metal ion binding' (Supplementary table categories, enriched for 'cytosol', 'chloroplast', 'nucleus', 'mitochondrion', 'cytoplasm', ‘ribosome', 'translation', 'nucleolus', ‘endoplasmic reticulum', 'oxidation-reduction', 'vacuole', and 'copper ion binding' (Supplementary table 6a). The 382 genes showing a significant interaction effect between the parental background and maternal environment showed an enrichment for the GO terms 'oxidation-reduction', 'extracellular region', 'transcript regulation',

191 'iron ion binding', and 'response to gibberellin' (Supplementary table 6b). Of note, the 'oxidation-reduction process' and 'transcript regulation' GO terms are enriched in the 193 upregulated genes of both MM and PI, which is not surprising since both GO terms are quite general and each represents many genes. These results show that the nutrition status of the E), modulate mRNA abundances in dry seeds of tomato.

A

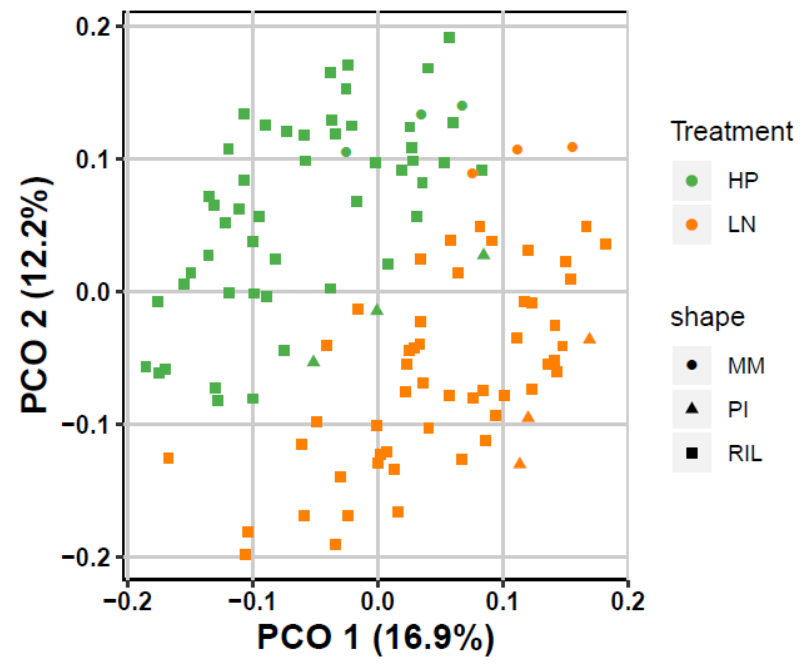

B

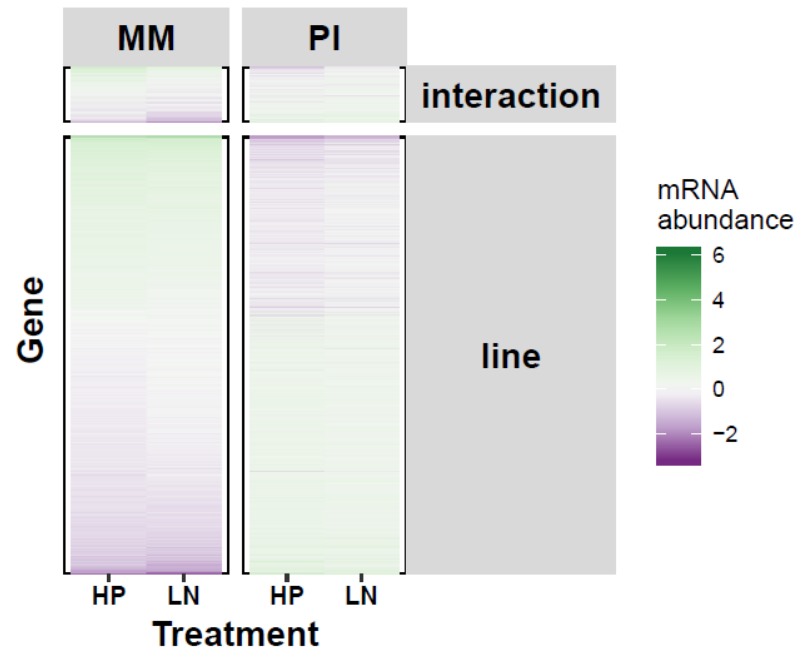

Figure 2: Nutrition status-related mRNA abundance differences between genotypes and seed development and maturation environments. (A) The first two axes of a principal component 
analysis on the $\log _{2}$ ratio with the mean transcripts per million (TPM) values. The first axis (PCO1) explained $16.9 \%$ of the variance in the data, the second $12.2 \%$. Square symbols represent individual RILs, Moneymaker (MM) parental samples are represented by dots and $S$. pimpinellifolium (PI) parental samples by triangles. The colours indicate high phosphorous (HP; green) or low nitrogen (LN; orange) treatments applied to the mother plants. (B) Differentially abundant mRNAs in the two parental lines that are either not affected (line) or affected by treatment (interaction). Lower mRNA abundance is shown in purple and higher in green (see legend).

\section{Heritability and transgression in $m R N A$ abundances}

To estimate the contribution of genetic variation to differences in mRNA abundance between the genetic backgrounds (plant lines) and treatments (nutrient status), we calculated the Broad-Sense Heritability (BSH). In addition, replicated measurements in the parental lines were used to estimate non-genetic variance. We found 5,112 genes in HP and 5,332 genes in LN that showed significant heritability for mRNA abundance, of which 2,973 genes overlapped (39.8\%; permutation, FDR < 0.05; Figure 3A; Supplementary table 7a). Subsequently, we checked if genes with significant heritable contribution to mRNA abundance differences were predominantly affected by the maternal nutrient environment. However, we did not find such an enrichment for any of the overlapping groups of genes (hypergeometric test, $\mathrm{p}>0.01$; Supplementary figure 1A). We thus conclude that, overall, the number of genes with significant heritability for mRNA abundance were not specifically responsive to the maternal nutrient treatments. The genes with heritable mRNA abundance in HP alone were enriched for the GO terms: 'translation', 'ribosome', 'mitochondrion', and more (Supplementary table 7b). Those that showed significant heritability only in LN were enriched for the GO terms: 'ABA metabolic process', and others (Supplementary table 7b). The genes that showed significant heritability in both environments were enriched for various GO terms: 'oxidation-reduction process', 'ribosome/translation', 'nucleolus', 'cell wall', 'heme binding', 'ion binding', and 'vacuole' (Supplementary table 7b). 
232 beyond the parental means. We found significant transgression in mRNA abundance (trait) levels

233 for 1,043 genes in the maternal HP treatment and 1,145 genes in the maternal LN treatment

234 (permutation, FDR < 0.05; Supplementary table 8a). This suggests a polygenic genetic 235 architecture for mRNA abundance. Of these, the mRNA abundances of 185 genes showed 236 significant transgression beyond the parental means in both treatments (Figure 3B). Also, here, 237 we tested for significant overlap with treatment-related genes. Yet, with $18 \%$ response to 238 treatment of the transgressive mRNAs, there was no significant enrichment for transgressive 239 mRNA abundances with treatment-related differences (hypergeometric test, $\mathrm{p}>0.01$;

240 Supplementary figure 1B). So, alike heritability, transgression is apparently not linked to a

241 reduction of nitrogen or increase of phosphorus content in the maternal growth environment.

242 Moreover, compared to genes showing significant heritability, many fewer GO terms were

243 enriched in the genes showing transgression, and those GO terms that were enriched, generally

244 had a lower level of significance. For genes showing transgression in HP alone, the GO terms

245 'cell periphery', 'positive gravitropism', ‘cysteine biosynthetic process', 'symporter activity’ and

246 'response to heat' were enriched. Whereas for genes only showing transgression in LN the GO-

247 terms 'beta-glucosidase activity', 'preprophase band', and 'phragmoplast' were enriched. The

248 GO term 'DNA-binding transcription factor activity' was enriched in genes showing

249 transgression in both environments (Supplementary table 8b). 
A

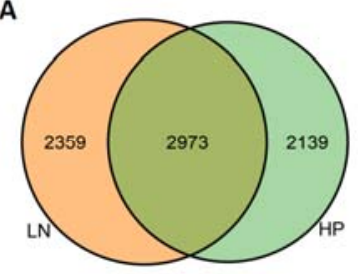

B

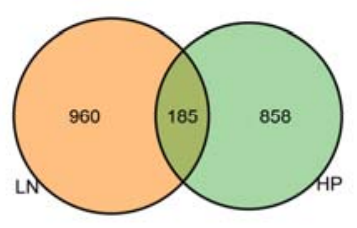

Figure 3: Venn diagrams showing the overlap and differences of (A) genes with significant heritable variance (Supplementary table 7a) and (B) genes exhibiting significant transgression (Supplementary table 8a), of mRNA abundance levels between LN (orange) and HP (green; FDR

The maternal nutrient environment produces specific eQTL landscapes.

Altogether, our analyses revealed both a considerable effect of the maternal nutrient environment

(HP versus LN) and a significant influence of genetic variation in the RIL panel (heritability) on

the detected mRNA abundance levels. By combining our constructed high density SNP genetic

map (Figure 1A, Supplementary table 1) with the obtained mRNA abundance dataset (Figure

2), we were able to identify eQTLs that potentially contribute to the variation in mRNA

abundance (Figure 4A-F). In other words, the identified eQTL loci have a high chance of

267 harboring polymorphic regulatory factors (e.g., genes or other genetic elements) for mRNA

268 abundance, prospectively explaining variation in the seed and germination trait phenotypes

269 observed.

We detected a maternal environment-specific trans-eQTL landscape, as the distribution of

the position of the trans-eQTLs was very different between the two environments. For the HP

272 environment, 4,281 eQTLs for 3,833 genes were identified, of which 2,247 were cis-eQTLs and

273 2,034 were trans-eQTLs. For the LN environment, 7,487 eQTLs were detected for 6,815 genes,

274 of which 2,356 were cis-eQTLs and 5,131 were trans-eQTLs $\left(\right.$ FDR $<0.05 ;-\log _{10}(\mathrm{p})>3.9$;

275 Figure 4A-D; Supplementary Table 9; Supplementary Table 10). A significant overlap 
276 between cis-eQTLs of the two environments was noted (Figure 4E; 1,506 overlapping cis-

277 eQTLs; 48.6\%; hypergeometric test, $\mathrm{p}<1 * 10^{-16}$ ). On the contrary, the trans-eQTLs were mainly

278 specific for each tested maternal environment (Figure 4F; 590 overlapping trans-eQTLs; 9.7\%;

279 hypergeometric test, $\mathrm{p}=1.0)$. However, both cis- and trans-eQTLs were not enriched for genes

280 with differentially abundant mRNA levels based on the maternal environment (hypergeometric

281 test, $\mathrm{p}>$ 0.01; Supplementary figure $\mathbf{2 A}$ and B). Together with the significant transgression

282 (Supplementary table 8a) and considerable heritability of mRNA abundances (Supplementary

283 table 7a; Figure 3A), this indicates that trans-eQTLs represent a genotype-specific interaction

284 with the maternal nutrient environment. Many different GO terms were found to be enriched in

285 the genes with environment specific eQTLs. For an overview see Supplementary table 11). 
A

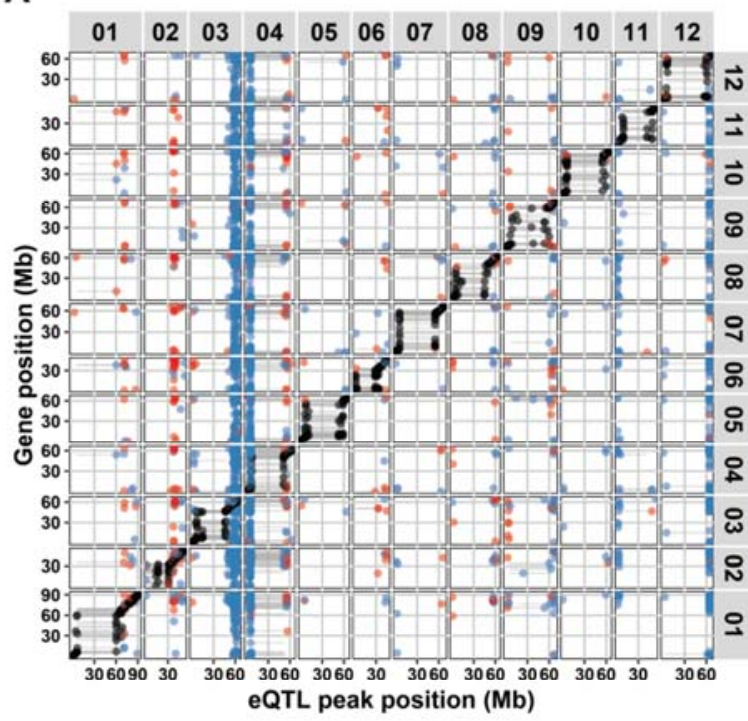

B

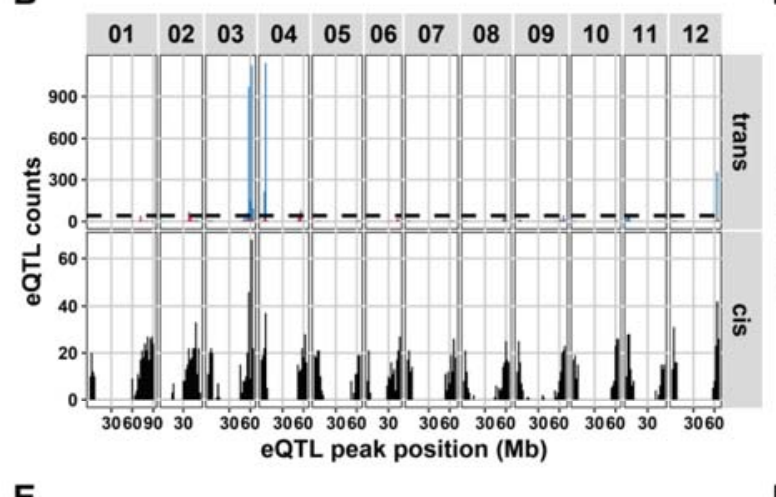

E

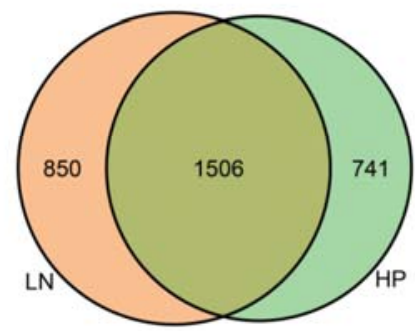

C

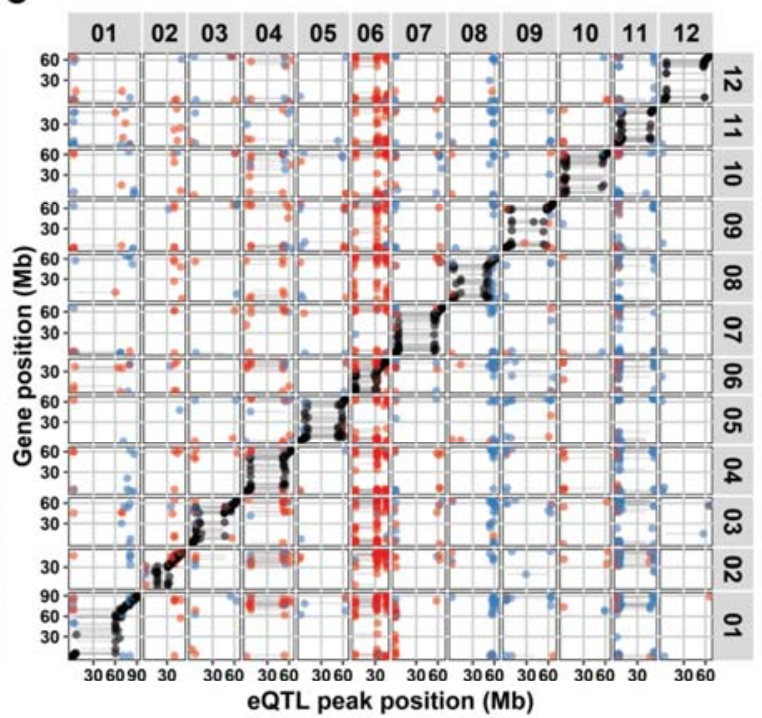

D

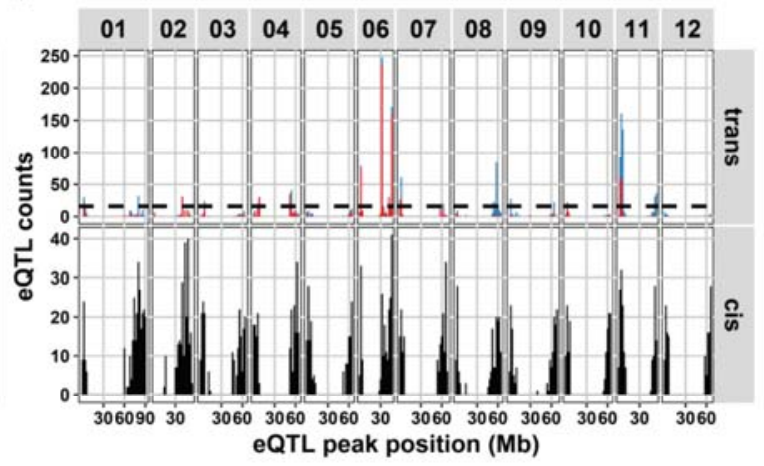

$\mathbf{F}$

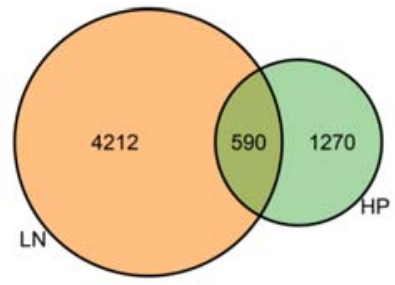

Figure 4: Characteristics of the detected eQTL landscapes in tomato dry seeds in (A, B) LN and (C, D) HP environments. (A, C) Cis-trans plots of eQTLs mapped $\left(-\log _{10}(\mathrm{p})>3.9\right)$. The positions (in $\mathrm{Mb}$, per chromosome) of the eQTL peaks are plotted on the $\mathrm{x}$-axis and the positions of the corresponding genes on the y-axis. Chromosome numbers are indicated on the top and right (grey labels). Colored dots indicate cis-eQTLs (black), eQTLs associated with higher mRNA abundance due to the MM allele (blue dots) or with higher abundance by the PI allele (red dots). (B, D) Histograms showing the distribution of the amount of cis- (lower panel) and trans (upper panel)-eQTLs over the chromosomes, arranged by eQTL peak location counted per 2 million bases $(\mathrm{Mb})$ bins. The dashed lines in the trans-eQTL panels indicate the threshold for calling a trans-band (poisson distribution, $\mathrm{p}<0.0001$ ). (E) The overlap of cis-eQTLs in the two treatments and $(\mathbf{F})$ the overlap of trans-eQTLs in the two maternal environments. 
The majority of the trans-eQTLs clustered in maternal nutrient environment-specific eQTL hotspots or trans-bands (Figure $\mathbf{4 A}, \mathbf{C}$ ). Hence, these genomic regions harbor the main loci underlying the genetic variation in environment-specific gene expression regulation in our treatment (59.3\% of HP total) and 4,181 of the trans-eQTLs in the LN treatment $(81.5 \%$ of LN total; Table 1).

Table 1: Overview of detected trans-band (TB) eQTLs. Indicated are given ID's, location on the physical genome (map position in $\mathrm{Mb}$ ), number of eQTLs underlying the trans-band (+ sign: MM > PI; - sign PI > MM), GO terms enriched in the eQTLs underlying the trans-band in either MM or PI and co-location with known phenotypic QTLs for germination $[15,17]$; + sign: MM > PI; - sign PI > MM).

\begin{tabular}{|c|c|c|c|c|c|}
\hline TB ID & Position & eQTLs & $\begin{array}{l}\text { GO enrichment } \\
\text { (+ MM higher) }\end{array}$ & $\begin{array}{l}\text { GO enrichment } \\
\text { (- PI higher) }\end{array}$ & $\begin{array}{l}\text { Germination QTL } \\
\text { Refs: }[15,17]\end{array}$ \\
\hline LN_TB1 & $\begin{array}{l}\text { ch03: } \\
56-64 \\
\mathrm{Mb}\end{array}$ & $\begin{array}{l}2369 \\
(2330+; 39-)\end{array}$ & $\begin{array}{l}\text { Translation; ribosome; nucleolus; } \\
\text { RNA binding; mitochondrion; } \\
\text { cell wall; and more }\end{array}$ & None & Th-I (LN-) \\
\hline LN_TB2 & $\begin{array}{l}\text { ch04:4-8 } \\
\mathrm{Mb}\end{array}$ & $\begin{array}{l}1348 \\
(1311+; 37-)\end{array}$ & $\begin{array}{l}\text { Telomere; nucleus; protein } \\
\text { binding; ubiquitin; and more }\end{array}$ & None & $\begin{array}{l}\text { Gmax water }(\mathrm{LN}+) ; \mathrm{T} 10 \\
\text { water }(\mathrm{LN}+) ; \mathrm{T} 10 \mathrm{NaCl}, \\
\text { mann, HT (LN+); T50 } \\
\text { water, mann, (LN+); AUC } \\
\text { water, mann (LN+) }\end{array}$ \\
\hline LN_TB3 & $\begin{array}{l}\text { ch04:54- } \\
56 \mathrm{Mb}\end{array}$ & $\begin{array}{l}99 \\
(45+; 54-)\end{array}$ & None & $\begin{array}{l}\text { Secretory vesicle; and } \\
\text { more }\end{array}$ & $\begin{array}{l}\text { Gmax } \mathrm{NaCl} \text {, mann }(\mathrm{LN}+) \text {; } \\
\mathrm{SW}(\mathrm{LN}+)\end{array}$ \\
\hline LN_TB4 & $\begin{array}{l}\text { ch12:62- } \\
66 \mathrm{Mb}\end{array}$ & $\begin{array}{l}365 \\
(348+; 17-)\end{array}$ & $\begin{array}{l}\text { Golgi; endosome; glycosylation; } \\
\text { ER; and more }\end{array}$ & None & None in LN \\
\hline HP_TB1 & $\begin{array}{l}\text { ch01:2-4 } \\
\mathrm{Mb}\end{array}$ & $\begin{array}{l}41 \\
(16+; 25-)\end{array}$ & None & None & None in HP \\
\hline HP_TB2 & $\begin{array}{l}\text { ch04:6-8 } \\
\mathrm{Mb}\end{array}$ & $\begin{array}{l}38 \\
(7+; 31-)\end{array}$ & None & $\begin{array}{l}\text { Heme binding; } \\
\text { oxidoreductase; iron } \\
\text { ion binding }\end{array}$ & $\begin{array}{l}\text { Gmax mann, HT (HP+); } \\
\text { Th-I (HP+) }\end{array}$ \\
\hline HP_TB3 & $\begin{array}{l}\text { ch06:2-4 } \\
\mathrm{Mb}\end{array}$ & $\begin{array}{l}96 \\
(5+; 91-)\end{array}$ & None & None & U8416 NaCl, HT (HP+) \\
\hline HP_TB4 & $\begin{array}{l}\text { ch06:32- } \\
34 \mathrm{Mb}\end{array}$ & $\begin{array}{l}254 \\
(12+; 242-)\end{array}$ & None & RNA processing & Th-T (HP+) \\
\hline HP_TB5 & $\begin{array}{l}\text { ch06:44- } \\
48 \mathrm{Mb}\end{array}$ & $\begin{array}{l}182 \\
(13+; 169-)\end{array}$ & None & $\begin{array}{l}\text { Tricarboxylic acid } \\
\text { cycle; plastid; } \\
\text { vacuolar membrane; } \\
\text { cell wall }\end{array}$ & $\begin{array}{l}\text { T10 NaCl, mann, HT } \\
(\mathrm{HP}+) ; \mathrm{T} 50 \mathrm{NaCl}, \mathrm{HT} \\
(\mathrm{HP}+) ; \mathrm{AUC} \mathrm{NaCl}(\mathrm{HP}+)\end{array}$ \\
\hline HP_TB6 & $\begin{array}{l}\text { ch07:0-2 } \\
\mathrm{Mb}\end{array}$ & $\begin{array}{l}77 \\
(32+; 45-)\end{array}$ & None & None & None in HP \\
\hline HP_TB7 & $\begin{array}{l}\text { ch08:58- } \\
60 \mathrm{Mb}\end{array}$ & $\begin{array}{l}83 \\
(80+; 3-)\end{array}$ & Vacuole; oxidoreductase; golgi & None & Th-D (HP+) \\
\hline
\end{tabular}




\begin{tabular}{|l|l|l|l|l|l|}
\hline HP_TB8 & $\begin{array}{l}\text { ch11:0- } \\
6 \mathrm{Mb}\end{array}$ & $\begin{array}{l}371 \\
(249+; 122-)\end{array}$ & $\begin{array}{l}\text { chromosome, centromeric region; } \\
\text { ubiquitin conjugating enzyme } \\
\text { activity }\end{array}$ & $\begin{array}{l}\text { Transferase activity; } \\
\text { hydrolase activity; } \\
\text { response to heat }\end{array}$ & None \\
\hline HP_TB9 & $\begin{array}{l}\text { ch11:52- } \\
54 \mathrm{Mb}\end{array}$ & $\begin{array}{l}64 \\
(63+; 1-)\end{array}$ & $\begin{array}{l}\text { Ribosome; nucleolus; translation; } \\
\text { and more }\end{array}$ & None & T10 mann (HP-) \\
\hline
\end{tabular}

314 Thus, trans-bands are a major explanatory factor for trans-eQTLs. In other words, a relatively

315 large proportion of trans-eQTLs are caused by a few pleiotropic major-effect loci. Remarkably,

316 the MM allele had a positive effect on mRNA abundance for the majority of the eQTLs of the

317 trans-bands in the LN soil environment, whereas this was not so prevalent in the HP environment

318 (Table 1; Figure 4A, C). Most of these trans-bands showed enrichment for specific GO terms,

319 such as 'translation' and 'specific cellular organelles' for LN and, 'oxidoreductase' and 'vacuole'

320 for HP. (Table 1, Supplementary table 12). Moreover, many of the trans-bands co-locate with

321 known QTLs for germination and seed traits (Table 1 [15, 17]). These eQTLs can therefore

322 contribute to uncovering the molecular genetic mechanisms underlying the germination and seed

323 trait QTLs. 


\section{Discussion}

325 Our RNA-sequencing data obtained from a Tomato RIL population (S. lycopersicum (cv. 326 Moneymaker; MM) x S. pimpinellifolium (G1.1554; PI)) [17, 49], allowed for the construction of 327 a detailed and high resolution genetic map, describing the genotypes using 4,515 SNP markers. 328 This is over five times more than previously reported in Kazmi et al., 2012 [71], which used 865 markers. However, intrinsic to RNA-seq data, only SNPs present in the coding parts of the genes 330 (mRNA's) could be used. Therefore, determining the exact locus where recombination took place would need additional genome sequencing as described in [70].

By measuring transcript levels (i.e. mRNA abundances) in the seeds of a tomato RIL population that had matured in different maternal nutrient environments, we show that the maternal environment affects both regulation and the genetic architecture of gene expression in progeny seeds. Especially, trans eQTLs proved environment specific, which is comparable to other species [57, 63-67, 72-74]. We found 3,833 genes ( $26 \%$ of all detected expressed genes in

337 the RILs), with an eQTL in HP and 6,815 genes ( $46 \%$ of all expressed genes in the RILs) with an eQTL in LN. This is comparable to the number detected by Ranjan et al. 2016 [75], who used the upper part of 5 day-old hypocotyls of introgression lines (ILs), developed from the wild desert-adapted species Solanum pennellii and domesticated Solanum lycopersicum cv. M82 [76], and found 5,300 genes ( $25 \%$ of total expressed genes) to have an eQTL, with roughly half in cis and half in trans. We also found this close to 50/50 ratio in the HP condition, whereas in the LN condition the ratio of cis/trans eQTLs was increased to 30/70. Research in yeast indicated that the

344 detection of trans-acting eQTLs is more strongly affected by the power of the study than 345 detection of cis-acting eQTLs [73]. So, it is likely that in our study we would have even more 346 trans-eQTLs relative to cis- eQTLs. 
347 By comparing two different maternal environments in a population originating from two different

348 genetic backgrounds, many different maternal environment specific eQTLs were detected. This

349 underlines the interplay between genetics and nutrient environment in our study. Yet, we expect

350 much of the variation caused by this interplay will be uncovered in future studies increasing

351 numbers of different timepoints, environments and genotypes. More detailed data on the number

352 and type of polymorphisms between tomato lines, such as frameshifts [77] and copy number

353 variations [35], could facilitate identification of the causal polymorphic genes in this and other

354 eQTL studies. Moreover, combining eQTLs with QTLs obtained using phenotypic trait data [12,

355 15, 17], as well as other molecular data such as proteomics and/or metabolomics [47], will

356 contribute to obtaining mechanistic insight on how genotypic variation leads to phenotypic

357 variation between individuals at a systemic level. Furthermore, these eQTLs could be used as a

358 lead in studies with a larger source of wild-genotypes and combined with GWAS [39-42, 44, 78],

359 to pinpoint causal polymorphisms underlying variation at both the molecular and phenotypic

360 levels. 


\section{Methods}

Plant lines, growth conditions, and nutrient treatments

The mother plants (maternal conditions) were cultivated as described in Kazmi et al. 2012 and

Geshnizjani et al. 2020 [15, 17], in the greenhouse at Wageningen University, the Netherlands. In short; the parental lines Solanum lycopersicum cv. Money maker (MM) and Solanum pimpinellifolium accession CGN14498 (PI) as well as the derived recombinant inbred lines

(RILs; [49]; Supplementary table 1) were grown on rockwool under standard nutrient conditions (14 mM Nitrate and $1 \mathrm{mM}$ Phosphate) with a $16 \mathrm{~h}$ light $\left(25^{\circ} \mathrm{C}\right)$ and $8 \mathrm{~h}$ darkness $\left(15^{\circ} \mathrm{C}\right)$ photoperiod. From the moment the first flower opened, the plants were fertilized with the specific nutrient solutions, low nitrate $(2.4 \mathrm{mM}$ Nitrate, $1 \mathrm{mM}$ Phosphate) and high phosphate (14 $\mathrm{mM}$ Nitrate, $5 \mathrm{mM}$ Phosphate) in two biological replicates per environment. The seeds were collected from healthy and ripe fruits and the pulp still attached to the seeds was removed with $1 \%$

374 hydrochloric acid $(\mathrm{HCl})$ and a mesh sieve. Water was used to remove the remaining $\mathrm{HCl}$ and pulp. For disinfection, seeds were treated with trisodium phosphate (Na3PO4.12H2O). Subsequently, seeds were dried at $20^{\circ} \mathrm{C}$ for 3 days on a clean filter paper in ambient conditions. The seeds were then stored in paper bags at room temperature.

We used $10 \mathrm{mg}$ grinded powder derived from 30 whole, dry, brushed, after-ripened seeds (12 months after harvest) of parental lines and the RILs grown under the different nutrient environments in a GGG design $[79,80]$ to extract total RNA. In total, 3 replicates per treatment for the parental lines where sequenced and 49 single RIL seed pools for HP and 52 single RIL 
plant isolation kit (Macherey-Nagel 740949) with on-column DNA digestion and adding Plant RNA isolation Aid (Life technologies) according to the manufacturer's protocol and instructions. sequenced using the Illumina HiSeq2500 sequencer, producing strand-specific single-end reads of 100 nucleotides. Raw sequence reads can be found in the Sequence Read Archive (SRA; www.ncbi.nlm.nih.gov/sra) under ID: PRJNA704909

\section{Alignment and SNP calling}

Reads were trimmed using Trimmomatic (version 0.33, [81] to remove low quality nucleotides.

Trimmed reads were subsequently mapped to the Tomato SL4.0 reference genome with the

ITAG4.0 annotation [82] using the HISAT2 software (version 2.1.0, [83] with the --dta-cufflinks

[84]. SNPs were called using bcftools mpileup with a minimum read depth of 3.

\section{Generation of a genetic map from RNA-seq data}

401 The genetic map used for mapping the eQTLs was made from the RNA-seq data following the 402 protocol described in Serin \& Snoek et al. 2017 [13] and Snoek et al. 2019 [69]. With the 403 following modifications: SNPs were filtered for those that were consistently found in all 404 replicates of the parental lines and observed in all RILs. Then the genotype per RIL was 405 determined per sliding bin of 100 SNPs where the mean position of those SNPs was taken as the physical position of the obtained marker. 
410 Before mRNA abundance analysis, between $12 \mathrm{M}$ and $31 \mathrm{M}$ reads per sample were mapped to the 411 SL4.0 genome with ITAG4.0 annotation [82] using HISAT2 as described above. The mRNA 412 abundance was quantified to counts using Stringtie [85] with the options -e, -B and -G. In R, the 413 counts were used to calculate transcripts per million (TPM). The TPM values were $\log _{2^{-}}$ 414 transformed by

$$
T P M_{l o g}=\log _{2}(T P M+1)
$$

415 Additionally, to use for statistics, also a ratio with the average was calculated, by

$$
T P M_{r a t, i, j}=\log _{2}\left(\frac{T P M_{i, j}}{\overline{T P M}_{j}}\right)
$$

416 Where the $\log _{2}$ was calculated for each transcript $i$ of sample $j$ by dividing over the average value 417 for that transcript $\overline{T P M}$ over all samples $j$. After transformation, the transcripts were filtered for $418 \mathrm{TPM}_{\log }>0$, and detection in all samples.

421 The analyses reported below were conducted in " $R$ " (version 3.5.3, x64)[86] with custom written 422 scripts, accessible via https://git.wur.nl/published_papers/sterken_tomato-eqtl_2021. For 423 analysis, the dplyr and tidyr packages were used for data organization [87, 88], and plots were 424 generated using ggplot2 [89].

426 Treatment related $m R N A$ abundance differences

427 The principal component analysis comparing the mRNA abundances was done on the $T P M_{\text {rat }^{-}}$ 428 transformed data, using the prcomp function in "R". The mRNA abundance differences between 


$$
T M P_{l o g, i}=T_{i}+e_{i}
$$

430 where $T P M_{l o g, i}$ is the abundance level of transcript $i$ (one of 14,772 transcripts) in $\operatorname{RIL} j(\mathrm{n}=55$

431 for the HP treatment and $\mathrm{n}=58$ for the $\mathrm{LN}$ treatment), $T$ is the treatment (HP or LN), and $e$ is the

432 error term. To reduce the chance of detecting differences due to genetic variation, a strict

433 multiple-testing correction was applied (Bonferroni) using p.adjust. The threshold for

434 significance was $-\log _{10}(\mathrm{p})>5.47(\mathrm{FDR}=0.05)$.

435 To determine the effect of treatment on the differences in mRNA abundance between the

436 parental lines, we ran a linear model explaining the differences due to treatment and line effects

437 on the MM and PI parental data. The model used was

$$
T M P_{l o g, i, j}=T_{i, j}+L_{i, j}+T_{i, j} \times L_{i, j}+e_{i, j}
$$

438 where $T P M_{l o g, i, j}$ is the abundance level of transcript $i$ (one of 14,772 transcripts) in parental 439 replicate $j(\mathrm{n}=3$ for both treatments for $\mathrm{MM}$ and $\mathrm{PI}), T$ is the treatment (HP or $\mathrm{LN}$ ), $L$ is the line 440 (MM or $\mathrm{PI}$ ), and $e$ is the error term. Values were corrected for multiple testing using p.adjust 441 following the Benjamini Hochberg algorithm. The thresholds for FDR $=0.05$ were: $-\log _{10}(\mathrm{p})=$ 4421.71 for line, $-\log _{10}(p)=2.08$ for treatment, and $-\log _{10}(p)=2.89$ for the interaction between line 443 and treatment. We took the most stringent $\mathrm{p}$ value, $-\log _{10}(\mathrm{p})=2.89$ as threshold to determine 444 significance.

\section{Transgression}

447 Transgression was calculated by counting the number of lines with expression levels beyond

448 three standard deviations from the mean of the parental lines (as in RB Brem and L Kruglyak $449[90]) ; \mu \pm 3^{*} \sigma$. This was done for both treatments separately. The lower boundary was 450 established by the parental line with the lowest mean, and the upper boundary was established by 
the parental line with the highest mean. The standard deviation used to determine transgression

$452(\sigma)$ was calculated as the pooled standard deviation of the two parental lines ( $\mathrm{n}=3$ for both).

454 were randomized over the line designations and the same test as above was conducted. This was

455 repeated 1000 times for each transcript, so the obtained values could be used as the by-chance

456 distribution. The $50^{\text {th }}$ highest value was used as the false discovery rate $(\mathrm{FDR})=0.05$ threshold.

\section{Heritability}

459 The heritability was calculated by estimating the genotypic variance in the RILs and the 460 remaining variance (e.g. measurement error) in the parental lines (as in JJ Keurentjes, J Fu, IR 461 Terpstra, JM Garcia, G van den Ackerveken, LB Snoek, AJ Peeters, D Vreugdenhil, M 462 Koornneef and RC Jansen [56]). This was done for both treatments separately, by

$$
H_{R I L}^{2}=\frac{V_{R I L}-V_{e}}{V_{R I L}}
$$

463 where $V_{R I L}$ is the variance within the RIL population and $V_{e}$ is the pooled variance of both 464 parental lines.

To establish whether the heritability was significant and not outlier-driven, we applied a

466 permutation approach (as in A Vinuela, LB Snoek, JA Riksen and JE Kammenga [91]). The trait 467 values were randomized over the line designations and the heritability calculation were repeated.

468 This was done 1000 times for each transcript to generate a by-chance distribution. The $50^{\text {th }}$ 469 highest value was used as the FDR $=0.05$ threshold. 
474 For eQTL mapping a single marker model was used, and was applied separately for both 475 treatments (as in $[65,92])$. QTLs were mapped using the model

$$
T P M_{l o g, i, j}=x_{j}+e_{j}
$$

476 where $T P M_{\text {log, }, i j}$ is the expression level of transcript $i$ (one of 14,772 transcripts) in RIL $j(\mathrm{n}=49$

477 for the HP treatment and $n=52$ for the LN treatment). The expression levels were explained over 478 the genotype on marker location $x(\mathrm{x}=1,2, \ldots, 4515)$ of RIL $j$.

479 To determine the reliability of the detected QTLs and correct for multiple testing, a 480 permutation approach was used. As in the other permutations, the expression levels were 481 randomly distributed over the lines and this randomized set was mapped again according to the 482 procedure described above, which was repeated 10 times. To determine the FDR, we applied a 483 correction for multiple testing under dependency [93]

$$
\frac{F D S}{R D S} \leq \frac{m_{0}}{m} \times q \times \log (m)
$$

484 where FDS (false discovery) is the number of eQTLs detected in the permutation and the RDS 485 (real discovery) is the number of eQTLs detected in the QTL mapping at a specific significance 486 level. The number of true null hypotheses tested $\left(m_{0}\right)$, was $14,772-R D S$, where the number of 487 hypotheses tested $(m)$ was the number of transcripts, 14,772. The q-value was set at 0.05 , which 488 led to a threshold of $-\log _{10}(\mathrm{p})=3.7$ for the $\mathrm{LN}$ treatment and $-\log _{10}(\mathrm{p})=3.9$ for the HP 489 treatment. To keep comparisons straightforward (similar effect sizes), analyses were conducted at 490 the most stringent threshold $\left(-\log _{10}(\mathrm{p})>3.9\right)$. 
494

495 confidence interval as well.

496

497 download and online exploration in TomQTL at http://www.bioinformatics.nl/TomQTL/, an 516 interactive website based on AraQTL [63] and WormQTL2 [74]. 


\section{Acknowledgements}

520 We thank Prof. Dr. Jan Kammenga of the Laboratory of Nematology of Wageningen University,

521 Prof. Dr. Dick de Ridder of the Laboratory of Bioinformatics of Wageningen University and

522 Prof. Dr. Berend Snel of the Theoretical Biology and Bioinformatics department of Utrecht

523 University for their support.

524

\section{Author contributions}

526 WL and HWMH conceived the study, NG, JR and LW performed the experiments, MGS, HN

527 and LBS analyzed and visualized the data, MGS and LBS wrote the manuscript with input from

$528 \mathrm{MvZ}, \mathrm{HN}, \mathrm{JJG}$, and WL. All authors approved the final version of this manuscript.

529

$530 \quad$ Funding

531 This work was supported by Technology Foundation (STW), which is part of the Netherlands

532 Organization for Scientific Research (NWO) (LW, JR, HN, WL). M.G.S. was supported by

533 NWO domain Applied and Engineering Sciences VENI grant (17282). 


\section{Supplementary tables and figures}

Supplementary table 1: Genetic map of the parental and Recombinant Inbred Lines used.

537 Matrix of the 101 lines used, 3 F1 heterozygotes (columns) and the 4,515 detected markers listed 538 per chromosome (ch01-ch12) (lines). The genotypes are likelihood based where "0" indicates a 539 locus derived from MM and "1" indicates a locus derived from PI. Chromosome number and 540 genomic position (basepair) are given in the first two columns. Position is the average basepair 541 position of the 100 SNPs sliding bin used to determine the parental origin of the locus.

543 Supplementary table 2: Introgression size statistics. Minimum, maximum, mean and median 544 introgression sizes per chromosome (first column).

Supplementary table 3: Outcome of a linear model to detect differentially abundant mRNAs

547 between the HP versus LN-treated RILs. For the mRNAs, two identifiers are given in the 548 columns: identifier, and Name. Furthermore, the location (chromosome number and genome 549 position of gene start in basepairs), orientation (+ or - strand), and size (length in basepairs) are 550 indicated. Then, the outcome of the linear model is listed, first the significance in $-\log _{10}(\mathrm{p})$ 551 followed by two types of corrections for multiple testing: Bonferroni (conservative, as used in the 552 main text) and Benjamini Hochberg False-discovery rate (FDR; less conservative for 553 comparison). The column effect describes the difference between HP and LN treated maternal 554 environment. A description of the effect direction (treatment) is given in the last column.

556 Supplementary table 4: Gene Ontology (GO) enrichment data of maternal environment-related 
(F), cellular component (C), and biological process $(\mathrm{P}), \mathrm{P}$ value (p.value), Total mRNA's

559 identified in mRNA bin and GO (in.set), total number of genes in GO (In.GO) and total mRNA set size (set.size).

Supplementary table 5: Outcome of a linear model to detect differentially abundant mRNAs

between the MM and PI parental lines and their interaction with the environment. For the mRNAs, two identifiers are given in the columns: identifier, and Name. Furthermore, the location (chromosome number and genome position of gene start in basepairs), orientation (+ or - strand), size (length in basepairs) are indicated. Then, the outcome of the linear model is listed, first the tested factor, then significance in $-\log _{10}(\mathrm{p})$ and a correction for multiple testing (Benjamini Hochberg (FDR)). The column effect describes the difference between the factors tested and the interpretation of the effect direction is given in the last column.

Supplementary table 6a: Gene Ontology enrichment analysis of mRNAs that are higher in parental lines MM (left), PI (middle) and their interaction (right). Significantly different genes were taken from the model (see methods and material) only including the parental lines. See legend table S4 for details and abbreviations.

Supplementary table 6b: Gene Ontology enrichment analysis of mRNA differences between the

578 parental lines and nutrient environment; higher in HP (left) or higher in LN (right). Significantly

579 different genes were taken from the model (see methods and material) including the parental lines and the nutritional environment. See legend table S4 for details and abbreviations. 
Supplementary table 7a: Heritability of mRNA abundances from the HP and LN maternal environments. The treatment column indicates the maternal nutrient environment, the mRNA ID is specified in the trait column. H2_keurentjes is the heritability, which was calculated using the genotypic variance ( $\mathrm{Vg}$ ) and the residual variance (Ve) as described in Keurentjes et al. (2007) [56]. The FDR column indicates the FDR $=0.05$ threshold as determined by 1,000 permutations.

The last two columns specify if an mRNA abundance was significantly heritable and whether it was specific for one or multiple maternal environments, or not (group).

Supplementary table 7b: Gene Ontology enrichment analysis of mRNAs with significant heritability.

Supplementary table 8a: Transgression for mRNA abundances from the HP and LN maternal environments in the RILs. The treatment column indicates the maternal environment, the mRNA

ID is specified in the trait column. The n_lines_transgression column specifies how many RILs

FDR $=0.05$ threshold as determined by 1,000 permutations. The last two columns specify if an mRNA abundance was significantly transgressive or not and whether it was specific for one or multiple maternal environments, or not (group).

600

Supplementary table 8b: Gene Ontology enrichment analysis of mRNAs with significant transgression. See legend table S4 for details and abbreviations.

Supplementary table 9: Number of eQTLs detected per chromosome and treatment (LN; upper 605 table, HP; lower table). Indicated are for all eQTLs, QTL type (cis or trans) and QTL effect 
found per chromosome per nutrient environment (+ or -). The last column indicates the number

607 of eQTLs in the trans-bands (TB).

608

609 Supplementary table 10: List with eQTLs mapped in both the LN and HP maternal nutrient 610 environments. First, the maternal environment is listed, second the mRNA ID (trait). Then

611 columns with the location information of the eQTL: chromosome number, location (bp; and the

612 confidence interval bp_left and bp_right), and the marker. Then, the significance in $-\log _{10}(\mathrm{p})$ is

613 given and the effect size (negative is higher in MM-derived loci; positive is higher in PI-derived

614 loci). Furthermore, the type of QTL is given (cis or trans) and whether the QTL is part of a trans-

615 band. Also, the variance explained by a single marker model is given (R2_sm). Subsequently, the 616 name and location (chromosome number and start of the gene in basepairs) of the mRNA is 617 listed.

619 Supplementary table 11: Gene Ontology enrichment in genes with an eQTL. See legend table 620 S4 for details and abbreviations.

622 Supplementary table 12: Gene Ontology enrichment in genes with eQTLs mapping to a trans623 band. See legend table S4 for details and abbreviations.

625 Supplementary table 13: Recombinant Inbred Lines per treatment.

627 Supplementary figure 1: Venn-diagrams showing (A) the overlap between all nutrient 628 treatment-affected mRNA abundances and HP and LN heritable mRNA abundances and (B) 
631 Supplementary figure 2: Venn-diagrams showing the overlap between treatment-affected mRNAs, (A) trans-eQTLs and (B) cis-eQTL mapped in the HP and LN nutrient environments.

\section{$636 \quad$ Figures}

637 Figure 1: (A) Genetic map showing the genotype of the RILs and parental lines. Dark blue 638 indicates MM (bottom horizontal line, with index 0), light blue indicates PI (horizontal line above 639 MM, with index 1). Shades between dark and light blue visualize the certainty of the estimate 640 that a locus corresponds to either MM or PI, depending on the SNPs identified (see legend above 641 the panel). (B) Allele frequency (percentage) of S. pimpinellifolium (PI) alleles for each marker

642 across the chromosomes, considering all RILs in the population. (C) Cumulative number of 643 recombination events per chromosome for the whole population. Chromosome numbers are 644 indicated above panels $\mathbf{A}$, position on the chromosomes (in $\mathrm{Mb}$ ) is shown on the $\mathrm{x}$-axis below 645 panel $\mathbf{C}$.

647 Figure 2: Nutrition status-related mRNA abundance differences. (A) The first two axes of a 648 principal component analysis on the $\log _{2}$ ratio with the mean transcripts per million (TPM) 649 values. The first axis (PCO1) explained 16.9\% of the variance in the data, the second $12.2 \%$. 650 Square symbols represent individual RILs, Moneymaker (MM) parental samples are represented 651 by dots and S. pimpinellifolium (PI) parental samples by triangles. The colours indicate high 652 phosphorous (HP; green) or low nitrogen (LN; orange) treatments. (B) Differentially abundant 
mRNAs in the two parental lines not affected by treatment (line) and affected by treatment

654 (interaction). Lower abundance is shown in purple and higher in green.

656 Figure 3: Venn diagrams showing the overlap and differences of (A) genes with significant 657 heritable variance and (B) genes exhibiting significant transgression, of mRNA abundance levels 658 between LN (orange) and HP (green; FDR < 0.05).

Figure 4: Characteristics of the detected eQTL landscapes in tomato dry seeds in (A, B) LN and (C, D) HP environments. (A, C) Cis-trans plots of eQTLs mapped $\left(-\log _{10}(\mathrm{p})>3.9\right)$. The positions of the eQTL peaks are plotted on the x-axis and the positions of the corresponding 663 genes on the y-axis. Chromosomes are indicated on the top and right in the grey labels. Colours 664 indicate cis-eQTL (black), eQTL associated with higher mRNA abundance due to the MM allele 665 (blue) or with higher abundance by the PI allele (red). (B, D) Histograms showing the distribution 666 of the cis- and trans-eQTL over the chromosomes, arranged by eQTL peak location counted per 6672 million bases $(\mathrm{Mb})$ bins. The dashed lines in the trans-eQTL panels indicate the threshold for 668 calling a trans-band (poisson distribution, $\mathrm{p}<0.0001$ ). (E) The overlap of cis-eQTL in the two treatments and $(\mathbf{F})$ the overlap of trans-eQTL in the two maternal environments.

671 Table 1: Overview of detected Trans-band (TB) eQTLs. Indicated are given ID's, location on the

672 physical genome (map position in $\mathrm{Mb}$ ), number of eQTLs underlying the trans-band (+ sign:

$673 \mathrm{MM}>\mathrm{PI}$; - sign PI > MM), GO terms enriched in the eQTLs underlying the trans-band in either

$674 \mathrm{MM}$ or PI and co-location with known phenotypic QTLs for germination [15, 17]. 


\section{References}

678 1. Rowse H, Finch-Savage W: Hydrothermal threshold models can describe the germination response of carrot (Daucus carota) and onion (Allium cepa) seed populations across both sub-and supra-optimal temperatures. New Phytologist 2003, 158(1):101-108.

2. Delouche J, Baskin C: Determinants of seed quality. SHORT COURSE FOR SEEDSMEN 1971, 14:53-68.

3. Delouche JC: Environmental effects on seed development and seed quality. HortScience 1980, 15:775-780.

4. Donohue K: Completing the cycle: maternal effects as the missing link in plant life histories. Philosophical Transactions of the Royal Society of London B: Biological Sciences 2009, 364(1520):1059-1074.

5. de Souza Vidigal D, He H, Hilhorst HWM, Willems LAJ, Bentsink L: Arabidopsis in the Wild-The Effect of Seasons on Seed Performance. Plants 2020, 9(5).

6. Schmuths H, Bachmann K, Weber WE, Horres R, Hoffmann MH: Effects of preconditioning and temperature during germination of 73 natural accessions of Arabidopsis thaliana. Annals of botany $2006,97(4): 623-634$.

7. Demir I, Mavi K, Oztokat C: Changes in germination and potential longevity of watermelon

8. He H, de Souza Vidigal D, Snoek LB, Schnabel S, Nijveen H, Hilhorst H, Bentsink L: Interaction between parental environment and genotype affects plant and seed performance in Arabidopsis. J Exp Bot 2014, 65(22):6603-6615. (Citrullus lanatus) seeds during development. New Zealand Journal of Crop and Horticultural Science 2004, 32(1):139-145. Arabidopsis. J Exp Bot 2014, 65(22).6603-6615.

9. Munir J, Dorn L, Donohue K, Schmitt J: The influence of maternal photoperiod on germination requirements in Arabidopsis thaliana. American Journal of Botany 2001, 88:1240-1249. 
701

702

703

704

705

706

707

708

709

710

10. Pourrat $Y$, Jacques $R$ : The influence of photoperiodic conditions received by the mother plant on morphological and physiological characteristics of Chenopodium polyspermum L. seeds. Plant Science Letters 1975, 4(4):273-279.

11. Alboresi A, Gestin C, LEYDECKER MT, Bedu M, Meyer C, TRUONG HN: Nitrate, a signal relieving seed dormancy in Arabidopsis. Plant, cell \& environment 2005, 28(4):500-512.

12. Geshnizjani N, Sarikhani Khorami S, Willems LAJ, Snoek BL, Hilhorst HWM, Ligterink W: The interaction between genotype and maternal nutritional environments affects tomato seed and seedling quality. J Exp Bot 2019, 70(10):2905-2918.

13. Serin EAR, Snoek LB, Nijveen H, Willems LAJ, Jimenez-Gomez JM, Hilhorst HWM, Ligterink W: Construction of a High-Density Genetic Map from RNA-Seq Data for an Arabidopsis Bay-0 $\mathrm{x}$ Shahdara RIL Population. Front Genet 2017, 8:201.

14. Khan N, Kazmi RH, Willems LA, van Heusden AW, Ligterink W, Hilhorst HW: Exploring the natural variation for seedling traits and their link with seed dimensions in tomato. PLOS One 2012, 7(8):e43991.

15. Geshnizjani N, Snoek BL, Willems LAJ, Rienstra JA, Nijveen H, Hilhorst HWM, Ligterink W: Detection of QTLs for genotype $x$ environment interactions in tomato seeds and seedlings. Plant, cell \& environment 2020.

16. Joosen RV, Arends D, Willems LA, Ligterink W, Jansen RC, Hilhorst HW: Visualizing the genetic landscape of Arabidopsis seed performance. Plant Physiol 2012, 158(2):570-589.

17. Kazmi RH, Khan N, Willems LA, Van Heusden AW, Ligterink W, Hilhorst HW: Complex genetics controls natural variation among seed quality phenotypes in a recombinant inbred population of an interspecific cross between Solanum lycopersicum $\times$ Solanum pimpinellifolium. Plant, cell \& environment 2012, 35(5):929-951. 
724 18. Schachtman DP, Reid RJ, Ayling SM: Phosphorus Uptake by Plants: From Soil to Cell. Plant

$725 \quad$ Physiol 1998, 116(2):447-453.

726 19. Urbanczyk-Wochniak E, Fernie AR: Metabolic profiling reveals altered nitrogen nutrient regimes

727 have diverse effects on the metabolism of hydroponically-grown tomato (Solanum

728 lycopersicum) plants. J Exp Bot 2005, 56(410):309-321.

729 20. Alboresi A, Gestin C, Leydecker MT, Bedu M, Meyer C, Truong HN: Nitrate, a signal relieving

730 seed dormancy in Arabidopsis. Plant, cell \& environment 2005, 28(4):500-512.

731 21. Duermeyer L, Khodapanahi, E., Yan, D., Krapp, A., Rothstein, S., \& Nambara, E. : Regulation of

732 seed dormancy and germination by nitrate. Seed Science Research 2018, 28(3):150-157.

733 22. Matakiadis T, Alboresi A, Jikumaru Y, Tatematsu K, Pichon O, Renou JP, Kamiya Y, Nambara E,

734 Truong HN: The Arabidopsis abscisic acid catabolic gene CYP707A2 plays a key role in nitrate

735 control of seed dormancy. Plant Physiol 2009, 149(2):949-960.

736 23. He R, Yu D, Li X, Duan G, Zhang Y, Tang D, Zhao X, Liu X: F-box gene FOA2 regulates GA- and

ABA- mediated seed germination in Arabidopsis. Science China Life sciences 2016, 59(11):1192-

1194.

739 24. Schauer N, Semel Y, Roessner U, Gur A, Balbo I, Carrari F, Pleban T, Perez-Melis A, Bruedigam C,

$740 \quad$ Kopka J: Comprehensive metabolic profiling and phenotyping of interspecific introgression

741 lines for tomato improvement. Nature biotechnology 2006, 24(4):447-454.

742 25. Giovannoni J: Molecular biology of fruit maturation and ripening. Annual review of plant

743 biology 2001, 52(1):725-749.

744 26. Tomato Genome C: The tomato genome sequence provides insights into fleshy fruit evolution. $745 \quad$ Nature 2012, 485(7400):635-641. 
27. Tomato Genome Sequencing C, Aflitos S, Schijlen E, de Jong H, de Ridder D, Smit S, Finkers R, Wang J, Zhang G, Li N et al: Exploring genetic variation in the tomato (Solanum section Lycopersicon) clade by whole-genome sequencing. Plant J 2014, 80(1):136-148.

28. Razifard H, Ramos A, Della Valle AL, Bodary C, Goetz E, Manser EJ, Li X, Zhang L, Visa S, Tieman D et al: Genomic Evidence for Complex Domestication History of the Cultivated Tomato in Latin America. Mol Biol Evol 2020, 37(4):1118-1132.

29. Doebley JF, Gaut BS, Smith BD: The molecular genetics of crop domestication. Cell 2006, 127(7):1309-1321.

30. McCouch S: Diversifying selection in plant breeding. PLOS Biol 2004, 2(10):e347.

31. Bauchet $G$, Munos S, Sauvage $C$, Bonnet J, Grivet $L$, Causse M: Genes involved in floral meristem in tomato exhibit drastically reduced genetic diversity and signature of selection. $B M C$ plant biology 2014, 14:279.

32. Wang Z, Hong Y, Zhu G, Li Y, Niu Q, Yao J, Hua K, Bai J, Zhu Y, Shi H et al: Loss of salt tolerance during tomato domestication conferred by variation in a $\mathrm{Na}(+) / \mathrm{K}(+)$ transporter. The $E M B O$ journal 2020:e103256.

33. Yang J, Wang $\mathrm{Y}$, Shen $\mathrm{H}$, Yang $\mathrm{W}$ : In silico identification and experimental validation of insertion-deletion polymorphisms in tomato genome. DNA research : an international journal for rapid publication of reports on genes and genomes 2014, 21(4):429-438.

34. Blanca J, Montero-Pau J, Sauvage C, Bauchet G, Illa E, Diez MJ, Francis D, Causse M, van der Knaap E, Canizares J: Genomic variation in tomato, from wild ancestors to contemporary breeding accessions. BMC Genomics 2015, 16:257.

35. Razali R, Bougouffa S, Morton MJL, Lightfoot DJ, Alam I, Essack M, Arold ST, Kamau AA, Schmockel SM, Pailles Y et al: The Genome Sequence of the Wild Tomato Solanum pimpinellifolium Provides Insights Into Salinity Tolerance. Front Plant Sci 2018, 9:1402. 
36. Lin T, Zhu G, Zhang J, Xu X, Yu Q, Zheng Z, Zhang Z, Lun Y, Li S, Wang X et al: Genomic analyses provide insights into the history of tomato breeding. Nat Genet 2014, 46(11):1220-1226.

37. Pascual L, Albert E, Sauvage C, Duangjit J, Bouchet JP, Bitton F, Desplat N, Brunel D, Le Paslier $\mathrm{MC}$, Ranc $\mathrm{N}$ et al: Dissecting quantitative trait variation in the resequencing era: complementarity of bi-parental, multi-parental and association panels. Plant science : an international journal of experimental plant biology 2016, 242:120-130.

38. Sauvage C, Segura V, Bauchet G, Stevens R, Do PT, Nikoloski Z, Fernie AR, Causse M: GenomeWide Association in Tomato Reveals $\mathbf{4 4}$ Candidate Loci for Fruit Metabolic Traits. Plant Physiol 2014, 165(3):1120-1132.

39. Ye J, Li W, Ai G, Li C, Liu G, Chen W, Wang B, Wang W, Lu Y, Zhang J et al: Genome-wide association analysis identifies a natural variation in basic helix-loop-helix transcription factor regulating ascorbate biosynthesis via D-mannose/L-galactose pathway in tomato. PLoS Genet 2019, 15(5):e1008149.

40. Zhang J, Zhao J, Xu Y, Liang J, Chang P, Yan F, Li M, Liang Y, Zou Z: Genome-Wide Association Mapping for Tomato Volatiles Positively Contributing to Tomato Flavor. Front Plant Sci 2015, 6:1042.

41. Bauchet G, Grenier S, Samson N, Segura V, Kende A, Beekwilder J, Cankar K, Gallois JL, Gricourt J, Bonnet J et al: Identification of major loci and genomic regions controlling acid and volatile content in tomato fruit: implications for flavor improvement. The New phytologist 2017, 215(2):624-641.

42. Zhao J, Sauvage C, Zhao J, Bitton F, Bauchet G, Liu D, Huang S, Tieman DM, Klee HJ, Causse M: Meta-analysis of genome-wide association studies provides insights into genetic control of tomato flavor. Nat Commun 2019, 10(1):1534. 
43. Vosman B, Van't Westende WPC, Henken B, van Eekelen H, de Vos RCH, Voorrips RE: Broad spectrum insect resistance and metabolites in close relatives of the cultivated tomato. Euphytica: Netherlands journal of plant breeding 2018, 214(3):46.

44. Chang J, Yu T, Yang Q, Li C, Xiong C, Gao S, Xie Q, Zheng F, Li H, Tian Z et al: Hair, encoding a single $\mathrm{C} 2 \mathrm{H} 2$ zinc-finger protein, regulates multicellular trichome formation in tomato. Plant $\mathrm{J}$ 2018, 96(1):90-102.

45. Albert E, Segura V, Gricourt J, Bonnefoi J, Derivot L, Causse M: Association mapping reveals the genetic architecture of tomato response to water deficit: focus on major fruit quality traits. $J$ Exp Bot 2016, 67(22):6413-6430.

46. Zhang S, Yu H, Wang K, Zheng Z, Liu L, Xu M, Jiao Z, Li R, Liu X, Li J et al: Detection of major loci associated with the variation of 18 important agronomic traits between Solanum pimpinellifolium and cultivated tomatoes. Plant J 2018, 95(2):312-323.

47. Kazmi RH, Willems LAJ, Joosen RVL, Khan N, Ligterink W, Hilhorst HWM: Metabolomic analysis of tomato seed germination. Metabolomics : Official journal of the Metabolomic Society 2017, 13(12):145

48. Celik I, Gurbuz N, Uncu AT, Frary A, Doganlar S: Genome-wide SNP discovery and QTL mapping for fruit quality traits in inbred backcross lines (IBLs) of solanum pimpinellifolium using genotyping by sequencing. BMC Genomics $2017,18(1): 1$.

49. Voorrips RE, Verkerke, W., Finkers, R., Jongerius, R. \& Kanne, J.: Inheritance of taste components in tomato. Acta Physiologiae Plantarum 2000(22):3.

50. Viquez-Zamora M, Caro M, Finkers R, Tikunov Y, Bovy A, Visser RG, Bai Y, van Heusden S: Mapping in the era of sequencing: high density genotyping and its application for mapping TYLCV resistance in Solanum pimpinellifolium. BMC Genomics 2014, 15:1152. 
51. Capel C, Yuste-Lisbona FJ, Lopez-Casado G, Angosto T, Cuartero J, Lozano R, Capel J: Multienvironment QTL mapping reveals genetic architecture of fruit cracking in a tomato RIL Solanum lycopersicum x S. pimpinellifolium population. TAG Theoretical and applied genetics Theoretische und angewandte Genetik 2017, 130(1):213-222. 2015, 128(10):2019-2035 .

53. de Souza Vidigal D, Willems L, van Arkel J, Dekkers BJW, Hilhorst HWM, Bentsink L: Galactinol as

54. Geshnizjani N, Ghaderi-Far F, Willems LAJ, Hilhorst HWM, Ligterink W: Characterization of and $2018, \mathbf{1 8}(1): 229$

55. Rothan C, Diouf I, Causse M: Trait discovery and editing in tomato. Plant J 2019, 97(1):73-90. using genome-wide gene expression quantitative trait loci. Proc Natl Acad Sci U S A 2007, 
58. Kawakatsu T, Huang SS, Jupe F, Sasaki E, Schmitz RJ, Urich MA, Castanon R, Nery JR, Barragan C,

59. West MA, Kim K, Kliebenstein DJ, van Leeuwen H, Michelmore RW, Doerge RW, St Clair DA:

60. Jimenez-Gomez JM, Wallace AD, Maloof JN: Network analysis identifies ELF3 as a QTL for the

61. Jansen RC, Nap JP: Genetical genomics: the added value from segregation. Trends Genet 2001, $17(7): 388-391$.

62. Terpstra IR, Snoek LB, Keurentjes JJ, Peeters AJ, van den Ackerveken G: Regulatory network

63. Nijveen H, Ligterink W, Keurentjes JJ, Loudet O, Long J, Sterken MG, Prins P, Hilhorst HW, de

64. Hartanto M, Joosen RVL, Snoek BL, Willems LAJ, Sterken MG, de Ridder D, Hilhorst HWM,

65. Snoek BL, Sterken MG, Bevers RPJ, Volkers RJM, Van't Hof A, Brenchley R, Riksen JAG, Cossins A, BMC Genomics 2017, 18(1):500. 
67. Cubillos FA, Stegle O, Grondin C, Canut M, Tisne S, Gy I, Loudet O: Extensive cis-regulatory variation robust to environmental perturbation in Arabidopsis. Plant Cell 2014, 26(11):42984310.

68. Sterken MG, Bevers RPJ, Volkers RJM, Riksen JAG, Kammenga JE, Snoek BL: Dissecting the eQTL micro-architecture in Caenorhabditis elegans. BioRxiv 2019.

69. Snoek BL, Volkers RJM, Nijveen H, Petersen C, Dirksen P, Sterken MG, Nakad R, Riksen JAG, allows identification of novel QTLs for complex life history traits. BMC Biol 2019, 17(1):24.

70. Demirci S, van Dijk AD, Sanchez Perez G, Aflitos SA, de Ridder D, Peters SA: Distribution, position and genomic characteristics of crossovers in tomato recombinant inbred lines derived from an interspecific cross between Solanum lycopersicum and Solanum pimpinellifolium. Plant J 2017, 89(3):554-564. interspecific cross between Solanum lycopersicum x Solanum pimpinellifolium. Plant, cell \& environment 2012, 35(5):929-951.

72. Li Y, Alvarez OA, Gutteling EW, Tijsterman M, Fu J, Riksen JA, Hazendonk E, Prins P, Plasterk RH, expression. Elife 2018, 7. 
75. Ranjan A, Budke JM, Rowland SD, Chitwood DH, Kumar R, Carriedo L, Ichihashi Y, Zumstein K,

$$
\text { Maloof JN, Sinha NR: eQTL Regulating Transcript Levels Associated with Diverse Biological }
$$

Processes in Tomato. Plant Physiol 2016, 172(1):328-340.

76. Eshed Y, Zamir D: An introgression line population of Lycopersicon pennellii in the cultivated tomato enables the identification and fine mapping of yield-associated QTL. Genetics 1995,

77. Kevei Z, King RC, Mohareb F, Sergeant MJ, Awan SZ, Thompson AJ: Resequencing at >/=40-Fold Inbred Line Population and Characterization of Frame-Shift InDels That Are Highly Likely to

78. Mata-Nicolas E, Montero-Pau J, Gimeno-Paez E, Garcia-Carpintero V, Ziarsolo P, Menda N,

79. Li Y, Breitling R, Jansen RC: Generalizing genetical genomics: getting added value from environmental perturbation. Trends Genet 2008, 24(10):518-524.

80. Li Y, Swertz MA, Vera G, Fu J, Breitling R, Jansen RC: designGG: an R-package and web tool for

81. Bolger AM, Lohse M, Usadel B: Trimmomatic: a flexible trimmer for Illumina sequence data.

82. Prashant S. Hosmani MF-G, Henri van de Geest, Florian Maumus, Linda V. Bakker, Elio Schijlen, Jan van Haarst, Jan Cordewener, Gabino Sanchez-Perez, Sander Peters, Zhangjun Fei, James J. 
of the tomato reference genome using single-molecule sequencing, $\mathrm{Hi}-\mathrm{C}$ proximity ligation and optical maps BioRxiv 2020.

83. Kim D, Langmead B, Salzberg SL: HISAT: a fast spliced aligner with low memory requirements. Nature methods 2015, 12(4):357-360.

84. Li H, Handsaker B, Wysoker A, Fennell T, Ruan J, Homer N, Marth G, Abecasis G, Durbin R, Genome Project Data Processing S: The Sequence Alignment/Map format and SAMtools.

85. Pertea M, Pertea GM, Antonescu CM, Chang TC, Mendell JT, Salzberg SL: StringTie enables

86. R-Core-Team: R: A Language and Environment for Statistical Computing. R Foundation for

87. Wickham HF, R.; Henry, L; Müller, K.: dplyr: A Grammar of Data Manipulation. 2018.

88. Wickham HH, L: tidyr: Easily Tidy Data with 'spread()' and 'gather()' Functions. 2018.

924 89. Wickham H: GGplot2: elegant graphics for data analysis. 2009.

925 90. Brem RB, Kruglyak L: The landscape of genetic complexity across 5,700 gene expression traits in yeast. Proc Natl Acad Sci U S A 2005, 102(5):1572-1577.

91. Vinuela A, Snoek LB, Riksen JA, Kammenga JE: Aging Uncouples Heritability and Expression-QTL in Caenorhabditis elegans. G3 (Bethesda) 2012, 2(5):597-605.

92. Sterken MG, van Bemmelen van der Plaat L, Riksen JAG, Rodriguez M, Schmid T, Hajnal A,

932 93. Benjamini Y, Daniel Yekutieli: The control of the false discovery rate in multiple testing under 
bioRxiv preprint doi: https://doi.org/10.1101/2021.03.29.437558; this version posted April 1, 2021. The copyright holder for this preprint (which

was not certified by peer review) is the author/funder, who has granted bioRxiv a license to display the preprint in perpetuity. It is made available under aCC-BY-NC-ND 4.0 International license.

934 94. Rockman MV, Skrovanek SS, Kruglyak L: Selection at linked sites shapes heritable phenotypic

935 variation in C. elegans. Science 2010, 330(6002):372-376.

936 95. Tian T, Liu Y, Yan H, You Q, Yi X, Du Z, Xu W, Su Z: agriGo v2.0: a GO analysis toolkit for the

937 agricultural community, 2017 update. Nucleic Acids Res 2017, 45(W1):W122-W129.

938 